\title{
Adenomatous polyposis coli heterozygous knockout mice display hypoactivity and age-dependent working memory deficits
}

\author{
Hisatsugu Koshimizu ${ }^{1,2}$, Yasuyuki Fukui ${ }^{3}$, Keizo Takao ${ }^{2,4}$, Koji Ohira 1,2, Koichi Tanda ${ }^{3,5}$, \\ Kazuo Nakanishi ${ }^{3}$, Keiko Toyama ${ }^{1,2}$, Masanobu Oshima ${ }^{6}$, Makoto Mark Taketo ${ }^{7}$ and \\ Tsuyoshi Miyakawa ${ }^{1,2,4 *}$ \\ ' Division of Systems Medical Science, Institute for Comprehensive Medical Science, Fujita Health University, Toyoake, Japan \\ ${ }^{2}$ Core Research for Evolutional Science and Technology (CREST), Japan Science and Technology Agency, Kawaguchi, Japan \\ ${ }^{3}$ Genetic Engineering and Functional Genomics Group, Frontier Technology Center, Graduate School of Medicine, Kyoto University, Kyoto, Japan \\ ${ }^{4}$ Section of Behavior Patterns, Center for Genetic Analysis of Behavior, National Institute for Physiological Sciences, Okazaki, Japan \\ ${ }^{5}$ Department of Pediatrics, Kyoto Prefectural University of Medicine, Kyoto, Japan \\ ${ }^{6}$ Division of Genetics, Cancer Research Institute, Kanazawa University, Kanazawa, Japan \\ Department of Pharmacology, Graduate School of Medicine, Kyoto University, Kyoto, Japan
}

\section{Edited by:}

Jeff Dalley, University of

Cambridge, UK

Reviewed by:

Jeff Dalley, University of

Cambridge, UK

Adam C. Mar, University of

Cambridge, UK

*Correspondence:

Tsuyoshi Miyakawa, Division of Systems Medical Science, Institute

for Comprehensive Medical

Science, Fujita Health University,

1-98 Dengakugakubo,

Kutsukake-cho, Toyoake

470-1192, Japan.

e-mail: miyakawa@fujita-hu.ac.jp
A tumor suppressor gene, Adenomatous polyposis coli (Apc), is expressed in the nervous system from embryonic to adulthood stages, and transmits the Wnt signaling pathway in which schizophrenia susceptibility genes, including T-cell factor 4 (TCF4) and calcineurin $(\mathrm{CN})$, are involved. However, the functions of Apc in the nervous system are largely unknown. In this study, as the first evaluation of Apc function in the nervous system, we have investigated the behavioral significance of the Apc gene, applying a battery of behavioral tests to Apc heterozygous knockout $\left(\mathrm{Apc}^{+/-}\right)$mice. $\mathrm{Apc}^{+/-}$mice showed no significant impairment in neurological reflexes or sensory and motor abilities. In various tests, including light/dark transition, open-field, social interaction, eight-arm radial maze, and fear conditioning tests, $\mathrm{Apc}^{+/-}$mice exhibited hypoactivity. In the eight-arm radial maze, $\mathrm{Apc}^{+/-}$mice 6-7 weeks of age displayed almost normal performance, whereas those 11-12 weeks of age showed a severe performance deficit in working memory, suggesting that Apc is involved in working memory performance in an age-dependent manner. The possibility that anemia, which $\mathrm{Apc}^{+/-}$mice develop by 17 weeks of age, impairs working memory performance, however, cannot be excluded. Our results suggest that Apc plays a role in the regulation of locomotor activity and presumably working memory performance.

Keywords: Apc, behavioral test battery, hypoactivity, locomotor activity, working memory performance

\section{INTRODUCTION}

Establishing animal models of psychiatric disorders is essential for investigating the pathogenesis/pathophysiology and treatment of the disorders (Gainetdinov et al., 2001; Arguello and Gogos, 2006; Powell and Miyakawa, 2006). In our previous study, we revealed that forebrain-specific calcineurin $(\mathrm{CN})$ knockout $(\mathrm{KO})$ mice have severe working/episodic-like memory deficits (Zeng et al., 2001), and exhibit a spectrum of abnormal behaviors related to schizophrenia (Miyakawa et al., 2003). We also identified the PPP3CC gene, which encodes the $\mathrm{CN}$ gamma catalytic subunit, as a novel potential schizophrenia susceptibility gene (Gerber et al., 2003). Those studies demonstrated that a comprehensive behavioral test battery with genetically engineered mice is a powerful tool to screen mouse models for human psychiatric disorders. We, therefore, have been applying this approach to various strains of mice bearing mutations on genes for $\mathrm{CN}$ signaling pathways and CN-related neural molecules (Takao and Miyakawa, 2006a; Takao et al., 2007).
In this study, we focused on a tumor suppressor gene, $A p c$. The Apc gene product is a $312 \mathrm{kDa}$ protein harboring multiple domains and binds to various proteins, including components of the Wnt signaling pathway, which is able to activate CN (Saneyoshi et al., 2002; Senda et al., 2007). In the Wnt signaling pathway that regulates cell proliferation and differentiation in the intestine, the skin, the immune system, and the brain, Apc controls the signaling pathway through complex formation with glycogen synthase kinase-3 $\beta$ (GSK-3 $\beta$ ), axin, and $\beta$-catenin. In the absence of Wnt signaling, the GSK$3 \beta /$ axin/Apc complex that is called "a destruction complex", constitutively phosphorylates $\beta$-catenin, which is then proteolytically degraded. The binding of Wnt to its specific receptor, Frizzled, inhibits the destruction complex formation, which then leads to stabilization of $\beta$-catenin in cytosol (van Noort et al., 2002; MacDonald et al., 2009). Cytoplasmic $\beta$-catenin subsequently translocates into the nucleus, where it regulates gene expression with a transcription factor of the T-cell factor (TCF)/lymphoid enhancer-binding factor (LEF) family, TCF4, which is involved 
in Apc mutation-induced intestinal tumorigenesis (Korinek et al., 1997). A large-scale genome-wide association study recently identified some schizophrenia susceptibility genes, one of which is TCF4 (Stefansson et al., 2009). In our previous study, using a statistical clustering of human post-mortem brains, we classified individuals into two clusters, one of which contained 16 of 18 schizophrenic patients, and found that TCF4 was significantly upregulated in the schizophrenia-enriched cluster (Yamasaki et al., 2008). A recent study showed increased levels of TCF/LEF-dependent transcription and expression of endogenous $\mathrm{Wnt} / \beta$-catenin target genes in cerebral cortical cell-specific Apc KO mice (Ivaniutsin et al., 2009). Additionally, Cui et al. reported that $A p c$ is associated with susceptibility for schizophrenia (Cui et al., 2005). On the other hand, most $\mathrm{Apc}^{+/-}$mice are anemic by 10 weeks of age (Moser et al., 1990) and show symptoms of either bleeding or anemia at 17 weeks of age (Oshima et al., 1995). In human familial adenomatous polyposis, which is caused by a mutation of the $A p c$ gene, polyps are formed mainly in the colon, whereas in $\mathrm{Apc}^{+/}$mice polyps mostly develop in the absorptive epithelial cells of the small intestine, but not in the colon, which leads to anemia (Taketo, 2006). In addition, $\mathrm{Apc}^{\mathrm{Min}}$ mice that carry a dominant mutation in the $A p c$ gene have decreased liver catalase activity and elevated plasma interleukin-6 levels, which are known to be involved in anemia (Mehl et al., 2005; Raj, 2009).

In our present study, to clarify the role of Apc in the nervous system, we subjected $\mathrm{Apc}^{+/-}$mice to a behavioral test battery, including neurological screen, hot plate, rotarod, light/dark transition, open-field, social interaction, startle response/prepulse inhibition, Porsolt forced swim, eight-arm radial maze, and fear conditioning tests (Table 1). Our data suggest that Apc could be involved in hypoactivity and impaired working memory, although it is possible that anemia caused by tumors (Moser et al., 1990; Oshima et al., 1995) leads to those deficits.

\section{MATERIALS AND METHODS ANIMALS AND EXPERIMENTAL DESIGN}

$\mathrm{Apc}^{+/-}$mice were generated as previously reported (Oshima et al., 1995). They were backcrossed onto a C57BL/6 J

Table 1 | Behavioral test battery of Apc ${ }^{+/-}$mice.

\begin{tabular}{llcl}
\hline Batch & Test & Age & Result \\
\hline 1st & General health test & $7-8 w$ & Table 2 \\
& Light-dark transition test & $7-9 w$ & Figure 1 \\
& Open-field test & $8-9 w$ & Figure 2 \\
& Hot plate test & $8-9 w$ & Table 2 \\
& Social interaction test & $8-9 w$ & Figure 3 \\
& Rotarod test & $8-9 w$ & Table 2 \\
& Prepulse inhibition test & $8-10 w$ & Figure 5 \\
& Porsolt forced swim test & $9-10 w$ & Figure 4 \\
& Eight-arm radial maze test & $11-12 w$ & Figures 6A,B \\
& Fear conditioning test & $15-16 w$ & \\
& Eight-arm radial maze test & $6-7 w$ & Figures 6C,D \\
& Fear conditioning test & $11-12 w$ & Figure 7
\end{tabular}

line for at least six generations. Mice were group housed (2-4 mice per cage) in a room with a $12 \mathrm{~h}$ light/dark cycle (lights on at 7:00 a.m.) with access to food and water ad libitum. Behavioral testing was performed between 9:00 a.m. and 6:00 p.m. except where otherwise indicated. After the tests, each apparatus was cleaned with diluted sodium hypochlorite solution to prevent a bias due to olfactory cues. All behavioral tests were conducted in a manner similar to those previously described (Miyakawa et al., 2003; Yamasaki et al., 2008). The raw data of behavioral tests, which are not described in this paper, are disclosed in the gene-brain-phenotyping database (http://www.mouse-phenotype.org). All behavioral testing procedures were approved by the Animal Care and Use Committee of Kyoto University Graduate School of Medicine. We prepared three independent groups of mice for behavioral tests. One group consisted of an equivalent number of $\mathrm{Apc}^{+/-}$mice and wild-type control littermates.

\section{NEUROLOGICAL SCREEN}

Neurological screening was conducted as previously described (Yamasaki et al., 2008). Whisker touch, ear twitch, and righting reflex were evaluated. A number of physical features, including the presence of whiskers or bald hair patches, were also recorded.

\section{HOT PLATE TEST}

The hot plate test was used to evaluate sensitivity to a painful stimulus. Mice were placed on a $55.0( \pm 0.3)^{\circ} \mathrm{C}$ hot plate (Columbus Instruments, Columbus, $\mathrm{OH}$ ), and latency to the first hind-paw response was recorded with a $15 \mathrm{~s}$ cut-off time. The hind-paw response was defined as either a foot shake or a paw lick.

\section{MOTER FUNCTION TESTS}

A wire hang test apparatus (O’Hara \& Co., Tokyo, Japan) was used to assess balance and grip strength. The apparatus consists of a box $(21.5 \times 22 \times 23 \mathrm{~cm})$ with a wire mesh grid $(10 \times 10 \mathrm{~cm})$ on its top, which can be inverted. The mouse was placed on the wire mesh, which was then inverted, causing the animal to grip the wire. Latency to fall was recorded, with a $60 \mathrm{~s}$ cut-off time. A grip strength meter (O'Hara \& Co.) was used to assess forelimb grip strength. Mice were lifted and held by their tail so that their forepaws could grasp a wire grid. The mice were then gently pulled backward by the tail with their posture parallel to the surface of the table until they release the grid. The peak force applied by the forelimbs of the mouse was recorded in newtons $(\mathrm{N})$. Each mouse was tested three times and the highest value obtained was used for statistical analysis. The rotarod test, using an accelerating rotarod (UGO Basile, Comerio, Italy), was performed by placing mice on rotating drums $(3 \mathrm{~cm}$ diameter $)$ and measuring the time each animal was able to maintain its balance on the rod. The speed of the rotarod accelerated from 4 to $40 \mathrm{rpm}$ over a $5 \mathrm{~min}$ period.

\section{LIGHT/DARK TRANSITION TEST}

The light/dark transition test was used to measure anxietylike behavior. The test was conducted as previously described (Takao and Miyakawa, 2006b). The apparatus used for the light/dark transition test consisted of a cage $(21 \times 42 \times 25 \mathrm{~cm})$ 
divided into two sections of equal size by a partition with a door (O'Hara \& Co.). One chamber was made of white plastic and brightly illuminated, whereas the other chamber was black and dark. Mice were placed in the dark side and allowed to move freely between the two chambers with the door open for $10 \mathrm{~min}$. The number of transitions between the two compartments, latency to first enter the lit chamber, distance traveled, and time spent in each chamber were recorded by ImageLD4 software (O’Hara \& Co.).

\section{OPEN-FIELD TEST}

Locomotor activity was measured using an open-field test as previously described (Yamasaki et al., 2008). Each mouse was placed in the corner of the open-field apparatus $(40 \times 40 \times 30 \mathrm{~cm}$; Accuscan Instruments, Columbus, $\mathrm{OH}$ ). The test chamber was illuminated at 100 lux. Total distance traveled, vertical activity (rearing measured by counting the number of photobeam interruptions), time spent in the center area, and beam-break counts for stereotypic behaviors were recorded. Center area was defined as $1 \mathrm{~cm}$ away from the walls. Data were collected for $120 \mathrm{~min}$.

\section{SOCIAL INTERACTION TEST}

The social interaction test was used to measure social behavior in mice. In the test, two mice of identical genotypes that were previously housed in different cages were placed in a box together $(40 \times 40 \times 30 \mathrm{~cm})$ and allowed to explore freely for $10 \mathrm{~min}$ (Tanda et al., 2009). Social behavior was monitored with a CCD camera connected to a Macintosh computer. Analysis was performed automatically using Image SI software (O'Hara \& Co.). The total number of contacts, total contact duration, mean duration per contact, and total distance traveled were measured. Active contact was defined as follows. Images were captured at one frame per second, and distance traveled between two successive frames was calculated for each mouse. If the two mice contacted each other and the distance traveled by either mouse was more than $2 \mathrm{~cm}$, the behavior was considered an "active contact."

\section{STARTLE RESPONSE/PREPULSE INHIBITION TESTS}

A startle reflex measurement system (O'Hara \& Co.) was used to measure startle response and prepulse inhibition (Yamasaki et al., 2008). A test session began by placing a mouse in a Plexiglas cylinder where it was left undisturbed for $10 \mathrm{~min}$. White noise (40 ms) was used as the startle stimulus for all trial types. The startle response was recorded for $140 \mathrm{~ms}$ (measuring the response every $1 \mathrm{~ms}$ ) starting with the onset of the prepulse stimulus. The background noise level in each chamber was $70 \mathrm{~dB}$. The peak startle amplitude recorded during the $140 \mathrm{~ms}$ sampling window was used as the dependent variable. A test session consisted of six trial types (two types for startle stimulus only trials and four types for prepulse inhibition trials). The intensity of startle stimulus was 110 or $120 \mathrm{~dB}$. The prepulse sound was presented $100 \mathrm{~ms}$ before the startle stimulus, and its intensity was 74 or $78 \mathrm{~dB}$. Four combinations of prepulse and startle stimuli (74-110, 78-110, 74-120, and $78-120 \mathrm{~dB}$ ) were employed. Six blocks of the six trial types were presented in pseudorandom order such that each trial type was presented once within a block. The average inter-trial interval was 15 s (range: 10-20s).

\section{PORSOLT FORCED SWIM TEST}

The Porsolt forced swim test was used to test for depressionlike behavior. The apparatus consisted of four plastic cylinders $(20 \mathrm{~cm}$ height $\times 10 \mathrm{~cm}$ diameter). The cylinders were filled with water $\left(23^{\circ} \mathrm{C}\right)$ up to a height of $7.5 \mathrm{~cm}$. Mice were placed into the cylinders, and their behavior was recorded over a 10 min test period. Data acquisition and analysis were performed automatically using Image PS software (O'Hara \& Co.). Distance traveled was measured by Image OF software (O’Hara \& Co.) using stored image files.

\section{EIGHT-ARM RADIAL MAZE TEST}

The eight-arm radial maze test was performed using a fully automated eight-arm radial maze apparatus (O'Hara \& Co.) to evaluate the spatial working memory (Yamasaki et al., 2008). The floor of the maze was made of white plastic and the transparent wall $(25 \mathrm{~cm}$ high $)$. Each arm $(9 \times 40 \mathrm{~cm})$ radiated from an octagonal central starting platform (perimeter $12 \times 8 \mathrm{~cm}$ ) like the spokes of a wheel. Identical food wells $(1.4 \mathrm{~cm}$ deep, $1.4 \mathrm{~cm}$ in diameter) with pellet sensors were placed at the distal end of each arm. The pellets sensors automatically recorded pellet intake by the mice. The maze was elevated $75 \mathrm{~cm}$ above the floor and placed in a sound proofed room with several extra-maze cues. The room was illuminated at 100 lux. During the experiment, the maze was maintained in a constant orientation. One week before pretraining, animals were deprived of food until their body weight was reduced to $80 \%$ to $85 \%$ of the initial level. Pretraining started on day eight. Each mouse was placed in the central starting platform and allowed to explore and to consume food pellets scattered on the whole maze for a $30 \mathrm{~min}$ period (one trial per mouse). After completion of the initial pretraining, mice received another pretraining trial to remove a single food pellet from each food well after being placed at the distal end of each arm. A trial was finished after the subject consumed the food pellet. This was repeated eight times, using eight different arms for each mouse. After these pretraining trials, actual maze acquisition trials were performed. For each trial, all eight-arms were baited with food pellets. Mice were placed on the central platform and allowed to obtain all eight pellets within $25 \mathrm{~min}$. A trial was terminated immediately after all eight pellets were consumed or $25 \mathrm{~min}$ had elapsed. An "arm visit" was defined as traveling down the arm for more than $5 \mathrm{~cm}$ from the central platform. The mice were confined in the center platform for $5 \mathrm{~s}$ after each arm choice. For mice 11-12 weeks of age, a delay (30 s for the 20th trial, 2 min for the 21st trial, and $5 \mathrm{~min}$ for the $22 \mathrm{nd}$ trial) was initiated after intake of the fourth pellet by confining the mice to the center platform. The animals went through one to four trials per day. For each trial, arm choices, latency to obtain all pellets, distance traveled, number of different arms chosen within the first eight choices, the number of arms revisited, and omission errors were automatically recorded. Data acquisition, control of guillotine doors, and data analysis were performed by Image RM software (O’Hara \& Co.).

\section{CONTEXTUAL AND CUED FEAR CONDITIONING TEST}

Contextual and cued fear conditioning tests were used to measure fear memory. Each mouse was placed in a test chamber 
$(26 \times 34 \times 29 \mathrm{~cm})$ inside a sound-attenuated chamber (chamber A; O'Hara \& Co.) and allowed to explore freely for $2 \mathrm{~min}$. A $60 \mathrm{~dB}$ white noise, which served as the conditioned stimulus (CS), was presented for $30 \mathrm{~s}$, followed by a mild ( $2 \mathrm{~s}, 0.5 \mathrm{~mA}$ ) footshock, which served as the unconditioned stimulus (US). Two more CSUS pairings were presented with a 2 min interstimulus interval. Context testing was conducted $24 \mathrm{~h}$ after conditioning in the same chamber. Cued testing with altered context was conducted after conditioning using a triangular box $(35 \times 35 \times 40 \mathrm{~cm})$ made of white opaque Plexiglas, which was located in a different room. The chamber of the test was illuminated at 100 lux. In cued testing with altered context, white noise was delivered from $180 \mathrm{~s}$ and continued until $6 \mathrm{~min}$. Data acquisition, control of stimuli (tones and shocks), and data analysis were performed automatically using Image FZ software (O'Hara \& Co.). Images were captured at 1 frame per second. For each pair of successive frames, the area in which the mouse moved was measured. When this area was below a threshold of 20 pixels, the behavior was judged as "freezing," i.e., complete lack of mobility in any parts of the body during a $1 \mathrm{~s}$ period. When the area equaled to or exceeded the threshold, the behavior was considered "non-freezing." The optimal threshold (amount of pixels) to judge freezing was determined by adjusting it to the amount of freezing measured by human observation. "Freezing" that lasted less than the defined time threshold of $2 \mathrm{~s}$ was not included in the analysis. The parameters were constant for all mice assessed.

\section{IMAGE ANALYSIS}

The applications used for the behavioral studies (Image LD4, Image SI, Image PS, Image OF, Image RM, and Image FZ) were developed by Dr. Tsuyoshi Miyakawa (available through O'Hara \& Co.) based on NIH Image program (NIH, Bethesda, $\mathrm{MD}$, available at http://rsb.info.nih.gov/nih-image/) and ImageJ (Imagejdev.Org, available at http://imagejdev.org/).

\section{STATISTICAL ANALYSIS}

Statistical analysis was conducted using StatView (SAS Institute, Cary, NC). Data were analyzed by one-way analysis of variance (ANOVA), repeated measures ANOVA, or correlation Z-test. Post hoc analyses were performed on all ANOVAs found to be significant. Values in graphs are expressed as mean \pm SEM.

\section{RESULTS}

\section{GENERAL BEHAVIORAL CHARACTERISTICS OF APC+/- MICE}

To evaluate the behavioral effect of Apc deficiency, we subjected $\mathrm{Apc}^{+/-}$mice and their wild-type littermates to a battery of behavioral tests. First, a neurological screen was performed using $\mathrm{Apc}^{+/-}$mice $7-8$ weeks of age. No abnormal neurological and physical features were found in $\mathrm{Apc}^{+/-}$mice (Table 2), except that $\mathrm{Apc}^{+/-}$mice weighed about $8 \%$ less than their wildtype littermates $\left(F_{1,39}=10.081, p=0.0030\right.$; Table 2$)$. There were no other obvious differences in physical characteristics. No significant differences were observed between genotypes in body temperature $(p=0.0898)$, the hot plate test $(p=$ $0.2250)$, the wire hang test $(p=0.3495)$, the grip strength test $(p=0.3740)$, and the accelerating rotarod tests $(p=$ 0.5063; Table 2), suggesting that $\mathrm{Apc}^{+/-}$mice had normal body
Table 2 | General health, neurological reflexes, and sensory and motor abilities in $\mathrm{Apc}^{+/-}$mice (+/-) and wild-type littermate controls $(+/+)$.

\begin{tabular}{|c|c|c|}
\hline & $+/+$ & $+/-$ \\
\hline \multicolumn{3}{|l|}{ PHYSICAL CHARACTERISTICS } \\
\hline Weight (g) & $22.8( \pm 0.5)$ & $20.9( \pm 0.3)^{* *}$ \\
\hline Whiskers (\% with) & 100 & 100 \\
\hline Fur (\% with normal far) & 95 & 100 \\
\hline Body temperature $\left({ }^{\circ} \mathrm{C}\right)$ & $36.9( \pm 0.2)$ & $36.5( \pm 0.2)$ \\
\hline \multicolumn{3}{|l|}{ SENSORY MOTOR REFLEX } \\
\hline Ear twitch (\% with quick response) & 100 & 100 \\
\hline Whisker twitch (\% with normal response) & 100 & 100 \\
\hline Righting reflex (\% with normal response) & 100 & 100 \\
\hline \multicolumn{3}{|l|}{ PAIN TESTS } \\
\hline Hot plate (latency; s) & $7.9( \pm 0.4)$ & $8.7( \pm 0.5)$ \\
\hline \multicolumn{3}{|l|}{ MOTOR TESTS } \\
\hline \multicolumn{3}{|l|}{ Wire hang } \\
\hline (Latency to fall; s) & $58.8( \pm 1.0)$ & $56.8( \pm 1.9)$ \\
\hline Grip strength $(N)$ & $0.816( \pm 0.018)$ & $0.792( \pm 0.02)$ \\
\hline \multicolumn{3}{|l|}{ Rotarod } \\
\hline \multirow[t]{6}{*}{ (Latency to fall; s) } & $104.4( \pm 12.5)$ & $112.1( \pm 17.0)$ \\
\hline & $128.9( \pm 9.9)$ & $139.8( \pm 12.2)$ \\
\hline & $144.1( \pm 12.4)$ & $152.8( \pm 12.8)$ \\
\hline & $155.6( \pm 14.9)$ & $158.1( \pm 15.4)$ \\
\hline & $178.0( \pm 16.4)$ & $176.7( \pm 15.2)$ \\
\hline & $149.9( \pm 17.4)$ & $179.5( \pm 16.2)$ \\
\hline
\end{tabular}

Apc ${ }^{+1-}$ mice, $n=18$; wild-type mice, $n=22$.

${ }^{* *} p=0.0030$, compared to wild-type.

temperature, nociception, neuromuscular strength, and motor coordination/learning, respectively.

\section{DECREASED LOCOMOTOR ACTIVITY IN APC + /- MICE}

Light/dark transition test was performed using $\mathrm{Apc}^{+/-}$mice 7-9 weeks of age. Distance traveled of $\mathrm{Apc}^{+/-}$mice was significantly decreased compared to wild-type mice in the light box $(p=0.0005)$ and dark box $(p=0.0309$; Figure 1A), and time spent in the light box did not differ significantly between genotypes ( $p=0.1167$; Figure 1B). Apc $c^{+/-}$mice showed a significant decrease in the number of transitions between the light and dark boxes ( $p=0.0042$; Figure 1C). The first latency to enter the light box was not significantly different between genotypes ( $p=0.1716$; Figure 1D). Next, Apc ${ }^{+/-}$mice at $8-9$ weeks of age were subjected to an open-field test. Total distance was significantly decreased in $\mathrm{Apc}^{+/-}$mice compared to wild-type mice in the first $30 \mathrm{~min}(p=0.0333)$ and in the entire $60 \mathrm{~min}$ (genotype effect, $p=0.1392$; genotype $\times$ time, $p=0.0481$; Figure 2A). Vertical activity of $\mathrm{Apc}^{+/-}$mice was significantly decreased $\left(p=0.0107\right.$; Figure 2B). Apc ${ }^{+/-}$mice showed a slight but non-significant decrease in time spent in the center area $(p=0.1278$; Figure 2C) and in stereotypic counts $(p=0.1639$; Figure 2D). A social interaction test was also performed on $\mathrm{Apc}^{+/-}$mice 8-9 weeks of age. Total duration of contacts, number of contacts, total duration of active contacts, mean duration per contact, and distance traveled were analyzed. No significant 

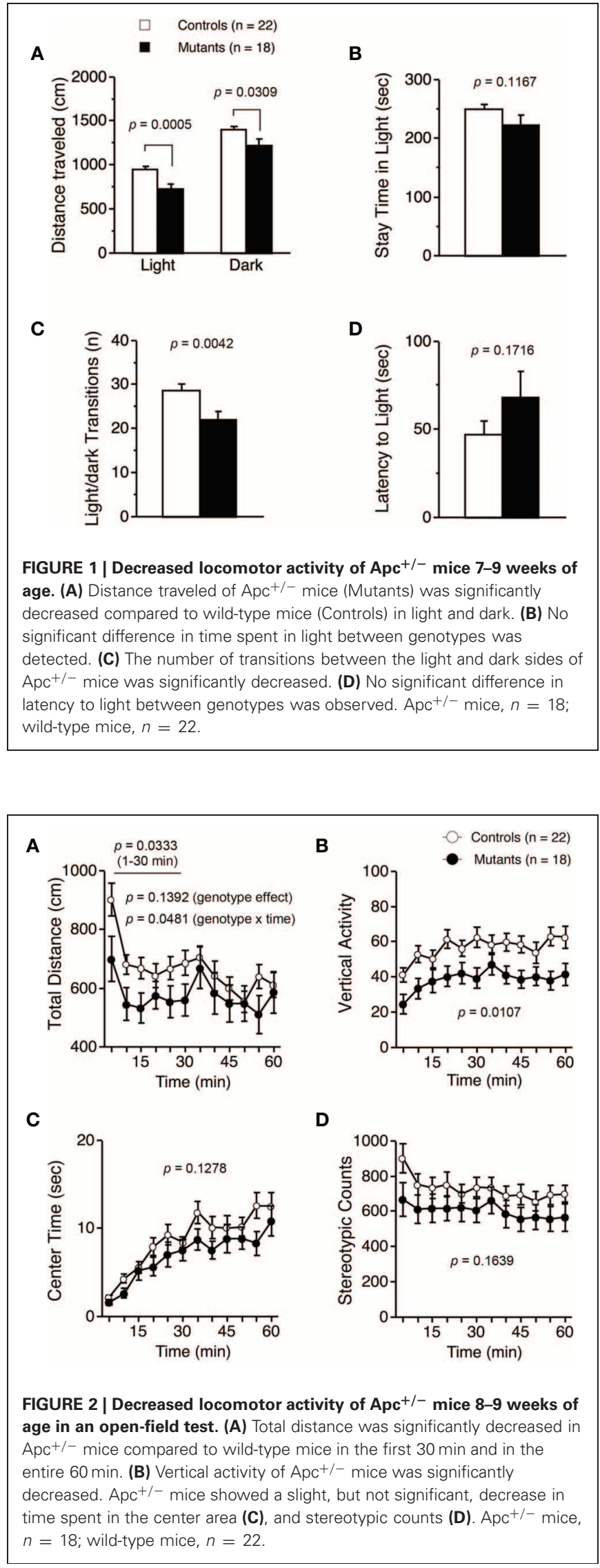

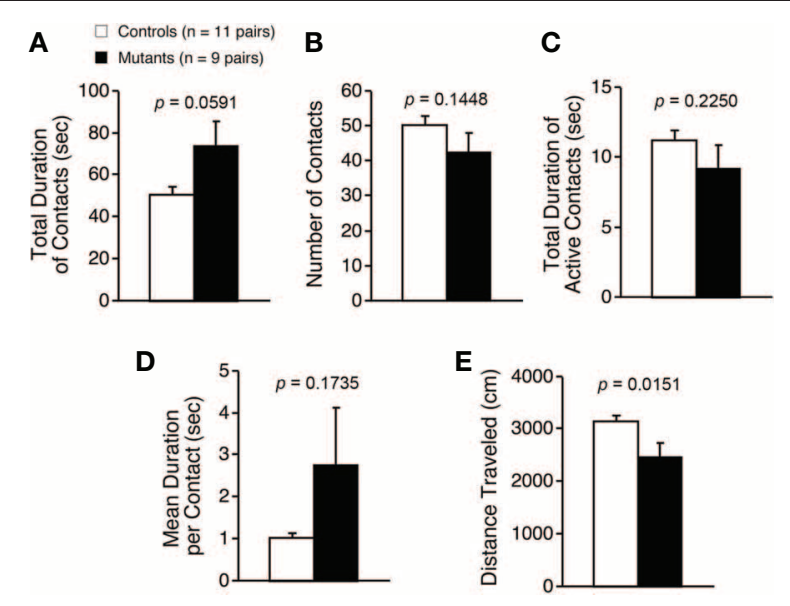

FIGURE 3 | Decreased locomotor activity of $\mathrm{Apc}^{+/-}$mice 8-9 weeks of age in a social interaction test. Total duration of contacts (A), number of contacts (B), total duration of active contacts (C), mean duration per contact (D), and distance traveled (E) were analyzed. Statistical difference between genotypes was not found in total duration of contacts, number of contacts, total duration of active contacts, or mean duration of per contacts. Distance traveled of $\mathrm{Apc}^{+/-}$mice was significantly decreased compared to wild-type mice. Apc ${ }^{+/-}$mice, $n=9$ pairs; wild-type mice, $n=11$ pairs.

difference between genotypes was detected in the total duration of contacts $(p=0.0591$; Figure 3A), number of contacts $(p=0.1448$; Figure 3B $)$, total duration of active contacts $(p=$ 0.2250 ; Figure 3C), and mean duration per contact $(p=0.1735$; Figure 3D), while distance traveled of $\mathrm{Apc}^{+/-}$mice was significantly decreased compared to wild-type mice $(p=0.0151$; Figure 3E). Taken together, these data suggest that locomotor activity was decreased in $\mathrm{Apc}^{+/-}$mice.

$\mathrm{Apc}^{+/-}$mice were next subjected to the Porsolt forced swim test. Although $\mathrm{Apc}^{+/-}$mice showed a significant increase in immobility on day 1 (Figure 4A left; genotype effect, $F_{1,38}=$ 4.588, $p=0.0387$ ), immobility during the whole experimental period did not significantly differ between genotypes (Figure 4A right; genotype effect, $F_{1,38}=0.158, p=0.6936$ ) on day 2 . Distance traveled did not significantly differ between genotypes on days 1 (Figure 4B left; genotype effect, $F_{1,38}=1.356, p=$ 0.2515 ) or 2 (Figure 4B right; genotype effect, $F_{1,38}=0.842$, $p=0.3645)$, suggesting that $\mathrm{Apc}^{+/-}$mice have normal activity under stress and that the decreased activity in $\mathrm{Apc}^{+/-}$mice observed in the other tests was not due to a motor function deficit.

\section{STARTLE RESPONSE/PREPULSE INHIBITION TESTS}

Startle amplitude for the 110 and $120 \mathrm{~dB}$ startle stimulus was significantly suppressed in $\mathrm{Apc}^{+/-}$mice $(p<0.0001$; Figure 5A). Because body weight of $\mathrm{Apc}^{+/-}$mice was approximately $8 \%$ lower than that of wild-type mice (Table 2), we assessed whether their startle amplitude correlated with their body weight. A correlation $Z$-test revealed that body weight did not significantly correlate with startle amplitude when the mice were startled by a 110 or $120 \mathrm{~dB}$ startle stimulus $(110 \mathrm{~dB}, p=0.2995 ; 120 \mathrm{~dB}$, $p=0.2208)$. Thus, the decreased body weight of $\mathrm{Apc}^{+/-}$mice did not account for the decreased startle response. On the other 


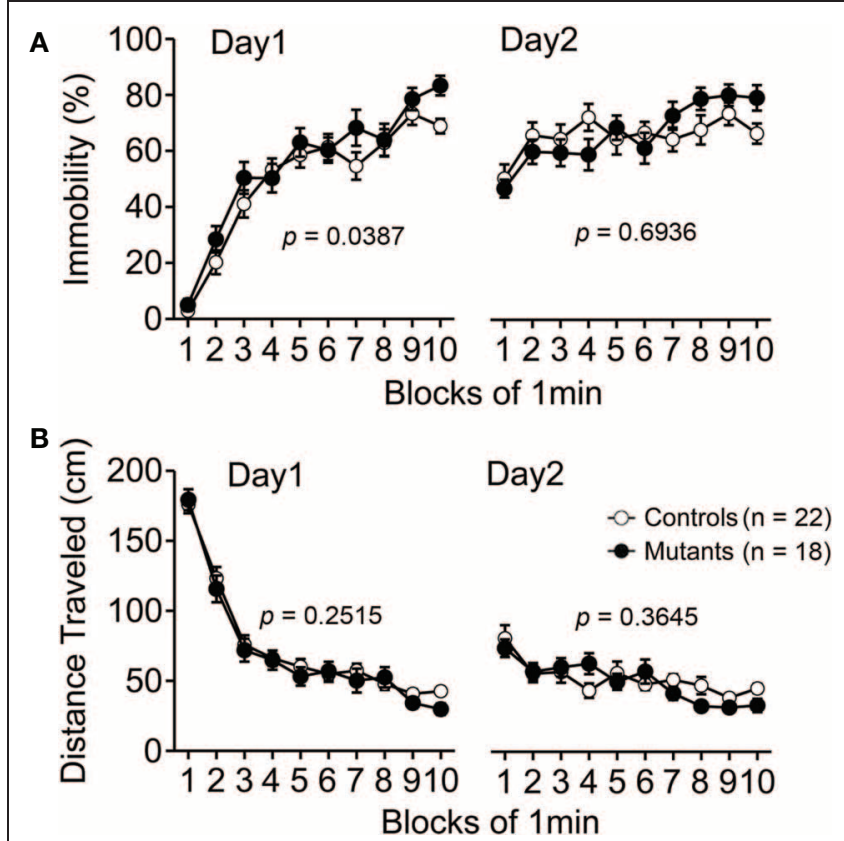

FIGURE 4 | Normal performance in behavioral despair of $\mathrm{Apc}^{+/-}$mice 9-10 weeks of age in the Porsolt forced swim test. (A) $\mathrm{Apc}^{+/-}$mice showed a significant decrease in immobility time compared to wild-type mice at day 1 , whereas there was no significant difference between genotypes at day 2. (B) No significant differences between genotypes in distance traveled were observed. Apc ${ }^{+/-}$mice, $n=18$; wild-type mice, $n=22$

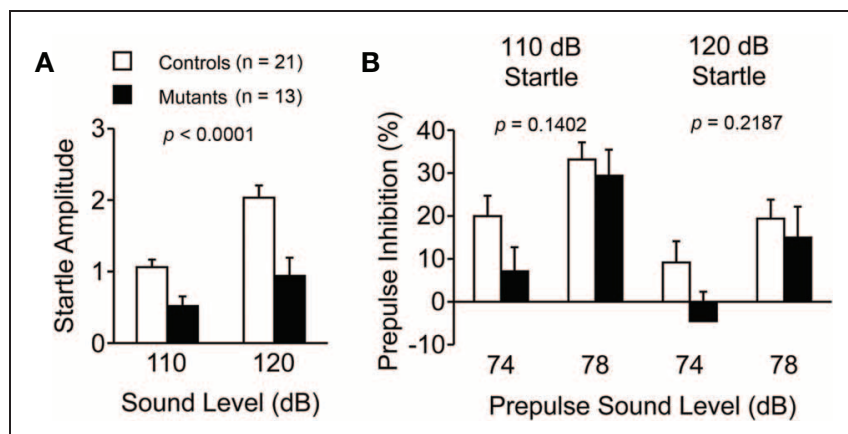

FIGURE 5 | Suppressed startle response and normal prepulse inhibition in $\mathrm{Apc}^{+/-}$mice 8-10 weeks of age. (A) Acoustic startle response for the 110 and $120 \mathrm{~dB}$ startle stimulus was significantly suppressed in $\mathrm{Apc}^{+/-}$mice. (B) $\mathrm{Apc}^{+/-}$mice showed normal prepulse inhibition for the 74 and $78 \mathrm{~dB}$ prepulse sound levels. $\mathrm{Apc}^{+/-}$mice, $n=13$; wild-type mice, $n=21$.

hand, prepulse inhibition also did not significantly differ between genotypes for either the 74 or $78 \mathrm{~dB}$ prepulse sound followed by either the 110 or $120 \mathrm{~dB}$ startle stimulus $(110 \mathrm{~dB}, p=0.1402$; $120 \mathrm{~dB}, p=0.2187$; Figure 5B).

\section{COGNITIVE PERFORMANCE IN APC $+/-$ MICE}

First, we conducted an eight-arm radial maze test on $\mathrm{Apc}^{+/-}$ mice. In adult $\mathrm{Apc}^{+/-}$mice 11-12 weeks of age, the number of different arm choices in the first eight entries was significantly lower than that of control mice (Figure 6A; $F_{1,32}=46.221$,
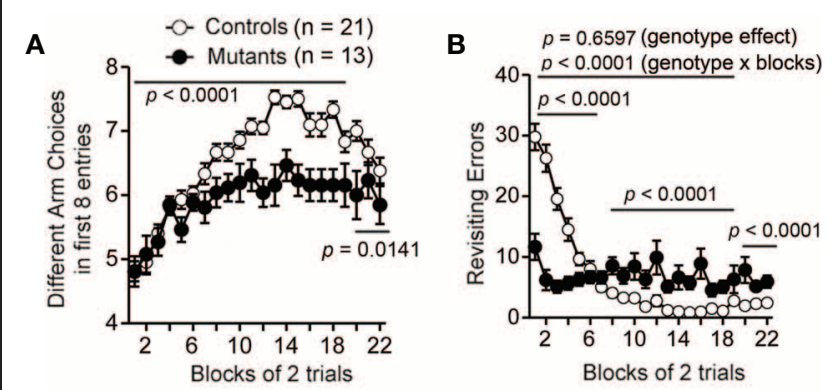

C

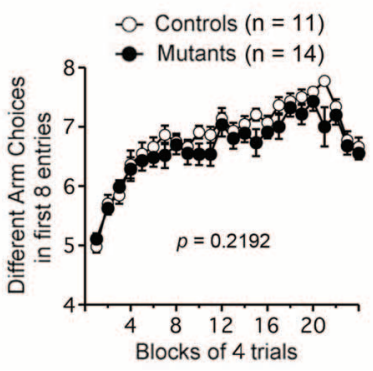

D

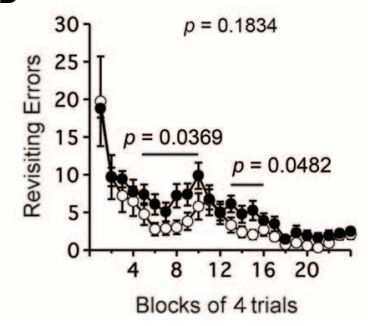

FIGURE 6 | Age-dependent impairment in working memory performance of $\mathrm{Apc}^{+/-}$mice in the eight-arm radial maze test. Adult $\mathrm{Apc}^{+/-}$mice 11-12 weeks of age showed impaired working memory performance (A-B). (A) Adult $\mathrm{Apc}^{+/-}$mice showed a significant decrease in the number of different arm choices in the first eight entries compared to controls during both trials without a delay (blocks 1-19) and trials with a delay (blocks 20-22). (B) Apc ${ }^{+/-}$mice exhibited a decrease in the number of revisiting errors during the earlier trials (blocks 1-7), and an increase in the later trials (blocks 8-19) and the trials with a delay (blocks 20-22). There was no significant difference in the number of revisiting errors between genotypes during the whole session. $\mathrm{Apc}^{+/-}$mice, $n=13$; wild-type mice, $n=21$. Young $\mathrm{Apc}^{+/-}$mice 6-7 weeks of age showed almost intact working memory performance in spatial memory tasks (C-D). (C) There was no significant difference between genotypes during the whole session in the number of different arm choices the first eight entries. (D) $\mathrm{Apc}^{+/-}$ mice exhibited a slight but significant increase in the number of revisiting errors during the earlier trials (blocks 5-10) and the later trials (blocks 13-16). There was no significant difference in the number of revisiting errors between genotypes during the whole session. $\mathrm{Apc}^{+/-}$mice, $n=14$; wild-type mice, $n=11$

$p<0.0001)$. Although there was no significant difference in the number of revisiting errors during the entire trials (Figure 6B; genotype effect, $F_{1,32}=2.136, p=0.6597$ ), there was a significant genotype $\times$ trial interaction between genotypes (Figure 6B; genotype $\times$ blocks, $\left.F_{15,480}=23.735, p<0.0001\right) . \mathrm{Apc}^{+/-}$ mice made significantly more revisiting errors than controls during the later trials of the test (Figure 6B; blocks 8-19; $F_{1,32}=$ 28.811, $p<0.0001$ ), while they made fewer errors during the earlier trials (Figure 6B; blocks 1-7; $F_{1,32}=40.255, p<$ 0.0001 ). This would be because during the earlier trials, the activity of wild-type mice was higher than that of $\mathrm{Apc}^{+/-}$mice and, therefore, wild-type mice had more opportunities to make errors. The number of different arm choices $\mathrm{Apc}^{+/-}$mice made during trials with a delay ( $30 \mathrm{~s}$ delay in the 20th block, 2 min delay in the 21 st block, and 5 min delay in the 22nd block) was significantly lower than those of wild-type mice (Figure 6A; blocks 20-22; $\left.F_{1,32}=10.394, p=0.0141\right)$. The number of revisiting errors of 
$\mathrm{Apc}^{+/-}$mice during trials with a delay was significantly higher than those of wild-type mice (Figure 6B; blocks 20-22; $F_{1,32}=$ 20.492, $p<0.0001)$. On the other hand, young $\mathrm{Apc}^{+/-}$mice 6-7 weeks of age showed no significant difference between genotypes in the number of different arm choices in the first eight entries (Figure 6C; $F_{1,23}=1.595, p=0.2192$ ) or in the number of revisiting errors (Figure $6 \mathrm{D} ; F_{1,23}=1.882, p=0.1834$ ) during the whole session. $\mathrm{Apc}^{+/-}$mice exhibited a slight but significant increase in the number of revisiting errors during the earlier trials (Figure 6D; blocks 5-10; $F_{1,23}=4.911, p=$ 0.0369 ) and the later trials (Figure 6D; blocks $13-16 ; F_{1,23}=$ 4.352, $p=0.0482$ ). Taken together, these findings suggest that working memory performance was impaired in an age-dependent manner in $\mathrm{Apc}^{+/-}$mice.

Finally, $\mathrm{Apc}^{+/-}$mice $11-12$ weeks of age were subjected to a fear conditioning test. $\mathrm{Apc}^{+/-}$mice showed higher levels of freezing after footshocks during the conditioning, context, and cued testing with altered testing before the auditory cue (Figure 7A; $p=0.0003, p<0.0001$, and $p<0.0001$ [before tone], respectively). Apc ${ }^{+/-}$mice showed normal freezing after the auditory cue (Figure 7A; after tone, $p=0.4285$ ), while the distance traveled immediately after footshocks 2 and 3 at the training phase was significantly lower (Figure 7B; Footshock 1, $p=0.1160$; Footshock 2, $p=0.0205$; Footshock 3, $p=0.0290)$.

\section{DISCUSSION}

In this study, we performed a behavioral test battery on $\mathrm{Apc}^{+/-}$ mice and several physical and behavioral characteristics were identified. First, general health, neurological reflexes, sensory abilities, and motor functions of $\mathrm{Apc}^{+/-}$mice and wild-type littermate control mice were similar on virtually all parameters at a young age (7-9 weeks of age) revealing that partial knockdown of Apc did not affect overall health and the fundamental abilities to conduct procedures required for the chosen memory tasks at the young age.

Second, $\mathrm{Apc}^{+/-}$mice exhibited decreased locomotor activity in various tests including light/dark transition, open-field, social interaction, eight-arm radial maze, and fear conditioning test. Performances of $\mathrm{Apc}^{+/-}$mice in hot plate, wire hang, and rotarod tests were normal. There were no significant differences between $\mathrm{Apc}^{+/-}$mice and their wild-type littermates in immobility and

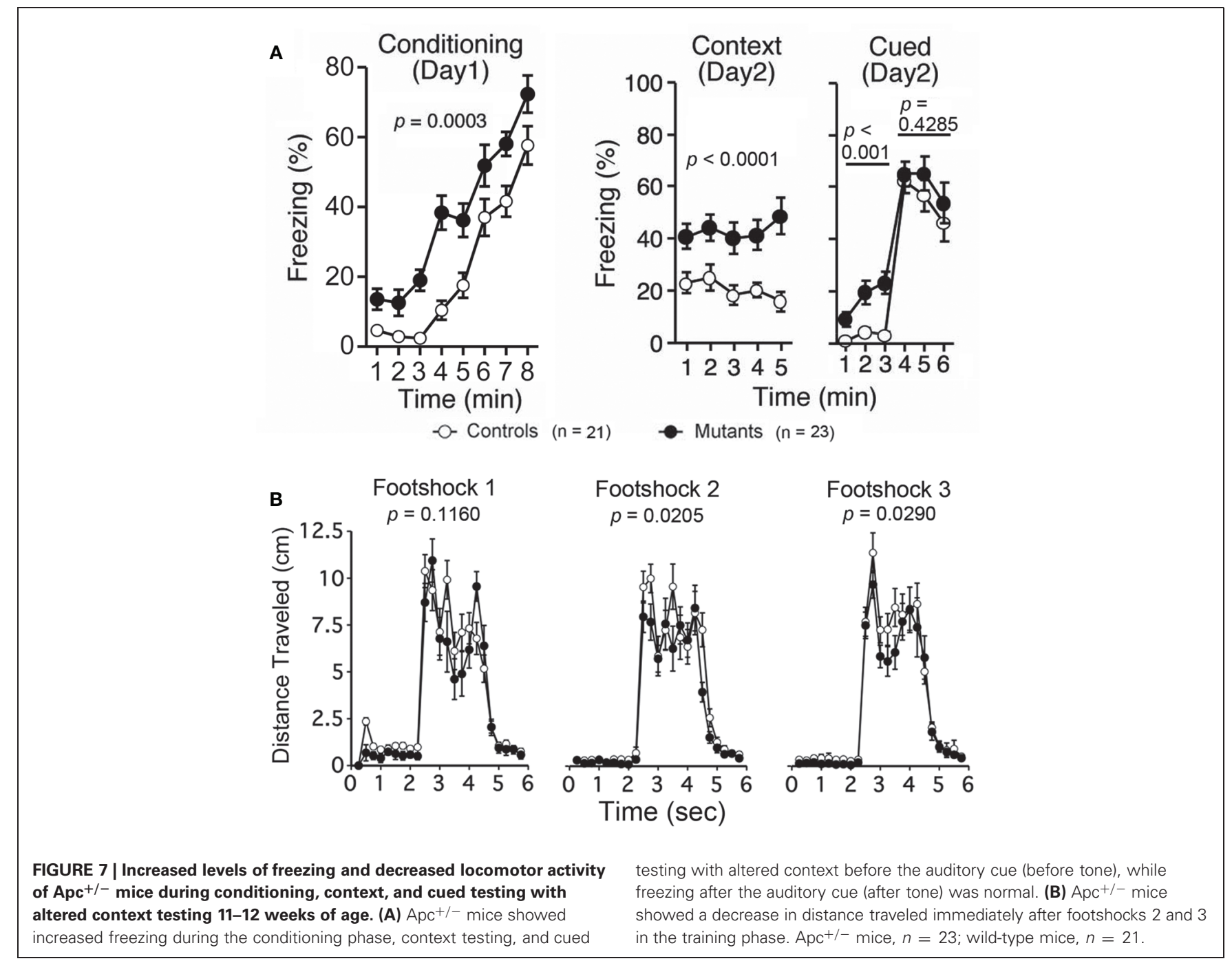


distance traveled in Porsolt force swim test. Additionally, in fear conditioning test, distance traveled immediately after the first electric footshock of $\mathrm{Apc}^{+/-}$mice was also normal. These findings suggest that $\mathrm{Apc}^{+/-}$mice had normal nociception, neuromuscular strength, and motor coordination/learning, and that there was no apparent motor deficit in $\mathrm{Apc}^{+/-}$mice. It is, therefore, likely that the decreased locomotor activity in $\mathrm{Apc}^{+/-}$mice would not be due to motor function deficits. $\mathrm{Apc}^{+/-}$mice subjected to light/dark transition, open-field, and social interaction tests were not anemic during these tests, because we performed those experiments in mice 6-9 weeks of age and also confirmed that those young animals did not have severe polyp formation or bleeding (data not shown), which causes anemia. Taken together, these findings suggest that partial knockdown of Apc itself, and not another factor, such as anemia, led to the decreased locomotor activity in young mice.

$\mathrm{Apc}^{+/-}$mice exhibited a decreased number of transitions in the light/dark transition test and increased freezing, and those changes were likely caused by decreased locomotor activity, which was widely observed in other tests. On the other hand, recent studies, including ours, have identified transgenic mice that exhibit both increased anxiety-related behaviors and decreased locomotor activity [e.g., Calpastatin KO (Nakajima et al., 2008), patDp/+ (Tamada et al., 2010), Steroidogenic Factor-1 KO (Zhao et al., 2008), etc.]. Because Apc is also expressed in the amygdala (Bhat et al., 1994; Senda et al., 1998; Wedgwood et al., 2000), which mediates anxiety- and fearrelated behaviors (LeDoux et al., 1990), Apc could be involved in anxiety-related behavior. It is possible that the decreased locomotor activity of $\mathrm{Apc}^{+/-}$mice is caused by increased anxiety.

Third, $\mathrm{Apc}^{+/-}$mice exhibited impaired working memory performance in the eight-arm radial maze in mice 11-12 weeks of age. Only a small impairment in working memory performance was observed in mice 6-7 weeks of age, suggesting that Apc regulates working memory performance in an age-dependent manner. On the other hand, several studies suggested that anemia influences cognitive function in rodents (Weinberg et al., 1979), macaques (Golub et al., 2006), and humans (Fowler et al., 1988; Denny et al., 2006). A mouse model of chronic cerebral hypoperfusion in which mice are subjected to bilateral common carotid artery stenosis shows impaired working memory (Shibata et al., 2007). Another mouse model of chronic cerebral hypoperfusion, muscarinic acetylcholine receptor $\mathrm{M}_{5} \mathrm{KO}$ mice, have reduced cerebral blood flow and impaired spatial and non-spatial memory (Araya et al., 2006). Furthermore, we demonstrated that adult C57BL/6 male mice subjected to bilateral common carotid artery stenosis, a mouse model of chronic cerebral hypoperfusion, exhibit a selective impairment of working memory. We observed that the blood vessels on the brain surface of $\mathrm{Apc}^{+/-}$mice at 17 weeks of age were less visible than those in wild-type when examined under a stereoscopic dissecting microscope with a magnification of $10 \times$ (data not shown), suggesting that those animals could have developed anemia. Therefore, the possibility that impaired working memory performance in $\mathrm{Apc}^{+/-}$mice at an adult age was caused by cerebral hypoperfusion cannot be excluded. Anemia is a confounding factor in the behavioral analysis of $\mathrm{Apc}^{+/-}$mice.
How does the partial knockdown of Apc in mice affect locomotor activity and working memory performance? It is possible that decreased expression of peripheral/somatic Apc is involved in these deficits. The body weight of $\mathrm{Apc}^{+/-}$mice was approximately $8 \%$ less than that of wild-type, which may be indicative of somatic abnormalities (e.g., impaired regulation of energy metabolism, decreased intestinal nutrient absorption, suppressed fat development) in $\mathrm{Apc}^{+/-}$mice that could directly or indirectly affect locomotor activity. On the other hand, the Apc protein is distributed ubiquitously in the central nervous system (CNS) and is highly expressed, particularly in the olfactory bulb, cerebral cortex, hippocampus, cerebellar cortex, and brain stem (Senda et al., 1998). In the CNS, Apc may have an important role in development and maintenance of the CNS via regulation of the Wnt signaling pathway, which is involved in neural development and plasticity processes, such as cell proliferation, differentiation, growth, and remodeling of the axons and dendrites, as well as activitydependent synaptic plasticity (Farías et al., 2010; Freese et al., 2010). The highest levels of Apc expression are found in the CNS during development and in adulthood (Senda et al., 2005). Considering that Apc negatively modulates TCF4 transcription factor-dependent gene expression by controlling the stability of $\beta$-catenin and that TCF4 is a schizophrenia susceptibility gene that was identified in a large-scale genomewide association study (MacDonald et al., 2009; Stefansson et al., 2009), it would be possible that decreased expression of Apc in the CNS causes an alteration in TCF4-dependent gene expression, which consequently leads to abnormal behavioral phenotypes in $\mathrm{Apc}^{+/-}$mice; however, behavioral phenotypes observed in $\mathrm{Apc}^{+/-}$mice were not identical with those of TCF4-overexpressing mice, which exhibit normal activity and deficits in contextual and cued fear conditioning (Brzózka et al., 2010). Similarly, behavioral phenotypes of $\mathrm{Apc}^{+/-}$mice were not totally identical to conditional $\mathrm{CN}$ KO mice, which exhibit multiple abnormal behaviors related to schizophrenia, including increased locomotor activity, decreased social interaction, impaired attentional function, impaired nesting behavior, and a severe working memory deficit (Zeng et al., 2001; Gerber et al., 2003; Miyakawa et al., 2003). In addition, it is also reported that $\mathrm{KO}$ of other Wnt pathway-related molecule, Dishevelled 1 (Dvl1) in mice led reduced social interaction, suppressed startle response, and decreased prepulse inhibition (Lijam et al., 1997), while $\mathrm{Apc}^{+/-}$mice showed a working memory performance deficit, a decrease in locomotor activity, suppressed startle response, and normal prepulse inhibition. It must be noted that because $\mathrm{Apc}^{+/-}$mice do not survive into adulthood because of tumor, age-related phenotypes, including those of schizophrenia, which are not seen until adulthood, would not be detectable in $\mathrm{Apc}^{+/-}$mice.

In summary, our behavioral test battery on $\mathrm{Apc}^{+/-}$mice revealed: (1) normal performance in general characteristics, (2) hypoactivity, and (3) impaired working memory performance at adult age. These data suggest that Apc is involved in locomotor activity and presumably working memory performance in an age-dependent manner. It remains unclear, however, whether the behavioral deficits in $\mathrm{Apc}^{+/-}$mice were caused by impaired 
neurodevelopment or impaired neurological function at the stage of behavioral testing. Additionally, because expression of Apc would be decreased not only in the CNS but also in the peripheral nervous system and other somatic tissues, the present study cannot fully determine whether the behavioral deficits in $\mathrm{Apc}^{+/-}$ mice were solely caused by deceased expression of Apc in the CNS. The possibility that partial knockdown of peripheral/somatic Apc directly or indirectly leads behavioral deficits in $\mathrm{Apc}^{+/-}$mice cannot be excluded. Therefore, other approaches using techniques such as inducible and brain region-specific knockdown of Apc are required to elucidate which tissue regions and developmental stage account for the hypoactivity and impaired working memory observed in $\mathrm{Apc}^{+/-}$mice, and to address whether and

\section{REFERENCES}

Araya, R., Noguchi, T., Yuhki, M., Kitamura, N., Higuchi, M., Saido, T. C., Seki, K., Itohara, S., Kawano, M., Tanemura, K., Takashima, A., Yamada, K., Kondoh, Y., Kanno, I., Wess, J., and Yamada, M. (2006). Loss of M5 muscarinic acetylcholine receptors leads to cerebrovascular and neuronal abnormalities and cognitive deficits in mice. Neurobiol. Dis. 24, 334-344.

Arguello, P. A., and Gogos, J. A. (2006). Modeling madness in mice: one piece at a time. Neuron 52, 179-196.

Bhat, R. V., Baraban, J. M., Johnson, R. C., Eipper, B. A., and Mains, R. E. (1994). High levels of expression of the tumor suppressor gene APC during development of the rat central nervous system. J. Neurosci. 14, 3059-3071.

Brzózka, M. M., Radyushkin, K., Wichert, S. P., Ehrenreich, H., and Rossner, M. J. (2010). Cognitive and sensorimotor gating impairments in transgenic mice overexpressing the schizophrenia susceptibility gene Tcf4 in the brain. Biol. Psychiatry $68,33-40$

Cui, D. H., Jiang, K. D., Jiang, S. D., Xu, Y. F., and Yao, H. (2005). The tumor suppressor adenomatous polyposis coli gene is associated with susceptibility to schizophrenia. Mol. Psychiatry 10, 669-677.

Denny, S. D., Kuchibhatla, M. N., and Cohen, H. J. (2006). Impact of anemia on mortality, cognition, and function in communitydwelling elderly. Am. J. Med. 119, 327-334.

Farías, G. G., Godoy, J. A., Cerpa, W., Varela-Nallar, L., and Inestrosa, N. C. (2010). Wnt signaling modulates pre- and postsynaptic maturation: therapeutic considerations. Dev. Dyn. 239, 94-101.

Fowler, M. G., Whitt, J. K., Lallinger, R. R., Nash, K. B., Atkinson, S.
S., Wells, R. J., and McMillan, C. (1988). Neuropsychologic and academic functioning of children with sickle cell anemia. J. Dev. Behav. Pediatr. 9, 213-220.

Freese, J. L., Pino, D., and Pleasure, S. J. (2010). Wnt signaling in development and disease. Neurobiol. Dis. 38, 148-153.

Gainetdinov, R. R., Mohn, A. R., and Caron, M. G. (2001). Genetic animal models: focus on schizophrenia. Trends Neurosci. 24, 527-533.

Gerber, D. J., Hall, D., Miyakawa, T., Demars, S., Gogos, J. A., Karayiorgou, M., and Tonegawa, S. (2003). Evidence for association of schizophrenia with genetic variation in the $8 \mathrm{p} 21.3$ gene, PPP3CC, encoding the calcineurin gamma subunit. Proc. Natl. Acad. Sci. U.S.A. 100, 8993-8998.

Golub, M. S., Hogrefe, C. E., Germann, S. L., Capitanio, J. P., and Lozoff, B. (2006). Behavioral consequences of developmental iron deficiency in infant rhesus monkeys. Neurotoxicol. Teratol. 28, 3-17.

Ivaniutsin, U., Chen, Y., Mason, J. O., Price, D. J., and Pratt, T. (2009). Adenomatous polyposis coli is required for early events in the normal growth and differentiation of the developing cerebral cortex. Neural Dev. 4, 3.

Korinek, V., Barker, N., Morin, P. J., van Wichen, D., de Weger, R., Kinzler, K. W., Vogelstein, B., and Clevers, H. (1997). Constitutive transcriptional activation by a beta-cateninTcf complex in APC-/- colon carcinoma. Science 275, 1784-1787.

LeDoux, J. E., Cicchetti, P., Xagoraris, A., and Romanski, L. M. (1990). The lateral amygdaloid nucleus: sensory interface of the amygdala in fear conditioning. J. Neurosci. 10, 1062-1069.

Lijam, N., Paylor, R., McDonald, M. P., Crawley, J. N., Deng, C.

how Apc is involved in the behavioral abnormalities related to psychiatric disease.

\section{ACKNOWLEDGMENTS}

This work was supported by KAKENHI (Grant-in-Aid for Scientific Research) on Young Scientists A (16680015), Scientific Research (B) (21300121), Exploratory Research (19653081), and Integrative Brain Research (IBR-shien) from the Ministry of Education, Science, Sports, and Culture of Japan from the Ministry of Education, Culture, Sports, Science, and Technology (MEXT) of Japan, grant from Neuroinformatics Japan Center (NIJC), and grants from CREST of Japan Science and Technology Agency (JST).

X., Herrup, K., Stevens, K. E. Maccaferri, G., McBain, C. J. Sussman, D. J., and Wynshaw-Boris, A. (1997). Social interaction and sensorimotor gating abnormalities in mice lacking Dvll. Cell 90, 895-905.

MacDonald, B. T., Tamai, K., and He, X. (2009). Wnt/beta-catenin signaling: components, mechanisms, and diseases. Dev. Cell 17, 9-26.

Mehl, K. A., Davis, J. M., Berger, F. G., and Carson, J. A. (2005). Myofiber degeneration/regeneration is induced in the cachectic ApcMin/+ mouse. J. Appl. Physiol. 99, 2379-2387.

Miyakawa, T., Leiter, L. M., Gerber, D. J., Gainetdinov, R. R., Sotnikova, T. D., Zeng, H., Caron, M. G., and Tonegawa, S. (2003). Conditional calcineurin knockout mice exhibit multiple abnormal behaviors related to schizophrenia. Proc. Natl. Acad. Sci. U.S.A. 100, 8987-8992.

Moser, A. R., Pitot, H. C., and Dove, W. F. (1990). A dominant mutation that predisposes to multiple intestinal neoplasia in the mouse. Science 247, 322-324.

Nakajima, R., Takao, K., Huang, S. M. Takano, J., Iwata, N., Miyakawa, T., and Saido, T. C. (2008). Comprehensive behavioral phenotyping of calpastatin-knockout mice. Mol. Brain 1, 7.

van Noort, M., Meeldijk, J., van der Zee, R., Destree, O., and Clevers, H. (2002). Wnt signaling controls the phosphorylation status of beta-catenin. J. Biol. Chem. 277, 17901-17905

Oshima, M., Oshima, H., Kitagawa, K., Kobayashi, M., Itakura, C., and Taketo, M. (1995). Loss of Apc heterozygosity and abnormal tissue building in nascent intestinal polyps in mice carrying a truncated Apc gene. Proc. Natl. Acad. Sci. U.S.A. 92, 4482-4486.
Powell, C. M., and Miyakawa, T. (2006). Schizophrenia-relevant behavioral testing in rodent models: a uniquely human disorder? Biol. Psychiatry 59, 1198-1207.

Raj, D. S. C. (2009). Role of interleukin6 in the anemia of chronic disease. Semin. Arthritis Rheum. 38, 382-388.

Saneyoshi, T., Kume, S., Amasaki, Y., and Mikoshiba, K. (2002). The $\mathrm{Wnt} /$ calcium pathway activates NFAT and promotes ventral cell fate in Xenopus embryos. Nature 417, 295-299.

Senda, T., Iino, S., Matsushita, K., Matsumine, A., Kobayashi, S., and Akiyama, T. (1998). Localization of the adenomatous polyposis coli tumour suppressor protein in the mouse central nervous system. Neuroscience 83, 857-866.

Senda, T., Iizuka-Kogo, A., Onouchi, T., and Shimomura, A. (2007) Adenomatous polyposis coli (APC) plays multiple roles in the intestinal and colorectal epithelia. Med. Mol. Morphol. 40, 68-81.

Senda, T., Shimomura, A., and IizukaKogo, A. (2005). Adenomatous polyposis coli (Apc) tumor suppressor gene as a multifunctional gene. Anat. Sci. Int. 80, 121-131.

Shibata, M., Yamasaki, N., Miyakawa, T., Kalaria, R. N., Fujita, Y., Ohtani, R., Ihara, M., Takahashi, R., and Tomimoto, H. (2007). Selective impairment of working memory in a mouse model of chronic cerebral hypoperfusion. Stroke 38 , 2826-2832.

Stefansson, H., Ophoff, R. A., Steinberg, S., Andreassen, O. A., Cichon, S., Rujescu, D., Werge, T., Pietiläinen, O. P., Mors, O., Mortensen, P. B., Sigurdsson, E., Gustafsson, O., Nyegaard, M., Tuulio-Henriksson, A., Ingason, A., Hansen, T., Suvisaari, J., Lonnqvist, J., Paunio, T., Børglum, A. D., Hartmann, A., Fink-Jensen, A., 
Nordentoft, M., Hougaard, D., Norgaard-Pedersen, B., Böttcher, Y., Olesen, J., Breuer, R., Möller, H. J., Giegling, I., Rasmussen, H. B., Timm, S., Mattheisen, M., Bitter, I., Réthelyi, J. M., Magnusdottir, B. B., Sigmundsson, T., Olason, P., Masson, G., Gulcher, J. R., Haraldsson, M., Fossdal, R., Thorgeirsson, T. E., Thorsteinsdottir, U., Ruggeri, M. Tosato, S., Franke, B., Strengman, E., Kiemeney, L. A.; Genetic Risk and Outcome in Psychosis (GROUP), Melle, I., Djurovic, S., Abramova, L., Kaleda, V., Sanjuan, J., de Frutos, R., Bramon, E., Vassos, E., Fraser, G., Ettinger, U., Picchioni, M., Walker, N., Toulopoulou, T., Need, A. C., Ge, D., Yoon, J. L., Shianna, K. V., Freimer, N. B., Cantor, R. M., Murray, R., Kong, A., Golimbet, V., Carracedo, A., Arango, C., Costas, J., Jönsson, E. G., Terenius, L., Agartz, I., Petursson, H., Nöthen, M. M., Rietschel, M., Matthews, P. M., Muglia, P., Peltonen, L., St Clair, D., Goldstein, D. B., Stefansson, K., and Collier D. A. (2009). Common variants conferring risk of schizophrenia. Nature 460, 744-747.

Takao, K., and Miyakawa, T. (2006a). Investigating gene-tobehavior pathways in psychiatric disorders: the use of a comprehensive behavioral test battery on genetically engineered mice. Ann. N. Y. Acad. Sci. 1086, 144-159.

Takao, K., and Miyakawa, T. (2006b). Light/dark transition test for mice. J. Vis. Exp. 1, 104.

Takao, K., Yamasaki, N., and Miyakawa, T. (2007). Impact of brain-behavior phenotyping of genetically-engineered mice on research of neuropsychiatric disorders. Neurosci. Res. 58, 124-132.

Taketo, M. M. (2006). Mouse models of gastrointestinal tumors. Cancer Sci. 97, 355-361.

Tamada, K., Tomonaga, S., Hatanaka, F., Nakai, N., Takao, K., Miyakawa, T., Nakatani, J., and Takumi, T. (2010). Decreased exploratory activity in a mouse model of $15 q$ duplication syndrome; implications for disturbance of serotonin signaling. PLoS One 5, e15126. doi: 10.1371/journal.pone.0015126

Tanda, K., Nishi, A., Matsuo, N., Nakanishi, K., Yamasaki, N., Sugimoto, T., Toyama, K., Takao, K., and Miyakawa, T. (2009). Abnormal social behavior, hyperactivity, impaired remote spatial memory, and increased D1-mediated dopaminergic signaling in neuronal nitric oxide synthase knockout mice. Mol. Brain 2, 19
Wedgwood, S., Lam, W. K., Pinchin, K. M., Markham, A. F., Cartwright, E. J., and Coletta, P. L. (2000) Characterization of a brain-selective transcript of the Adenomatous polyposis coli tumor suppressor gene. Mamm. Genome 11, 1150-1153.

Weinberg, J., Levine, S., and Dallman, P. R. (1979). Long-term consequences of early iron deficiency in the rat. Pharmacol. Biochem. Behav. 11, 631-638.

Yamasaki, N., Maekawa, M., Kobayashi, K., Kajii, Y., Maeda, J., Soma, M., Takao, K., Tanda, K., Ohira, K., Toyama, K., Kanzaki, K., Fukunaga, K., Sudo, Y., Ichinose, H., Ikeda, M., Iwata, N., Ozaki, N., Suzuki, H., Higuchi, M., Suhara, T., Yuasa, S., and Miyakawa, T. (2008). AlphaCaMKII deficiency causes immature dentate gyrus, a novel candidate endophenotype of psychiatric disorders. Mol. Brain 1, 6.

Zeng, H., Chattarji, S., Barbarosie, M., Rondi-Reig, L., Philpot, B. D. Miyakawa, T., Bear, M. F., and Tonegawa, S. (2001). Forebrainspecific calcineurin knockout selectively impairs bidirectional synaptic plasticity and working/episodic-like memory. Cell 107, 617-629.

Zhao, L., Kim, K. W., Ikeda, Y., Anderson, K. K., Beck, L., Chase, S., Tobet, S. A., and Parker, K. L.
(2008). Central nervous systemspecific knockout of steroidogenic factor 1 results in increased anxietylike behavior. Mol. Endocrinol. 22, 1403-1415.

Conflict of Interest Statement: The authors declare that the research was conducted in the absence of any commercial or financial relationships that could be construed as a potential conflict of interest.

Received: 26 September 2011; accepted: 06 December 2011; published online: 21 December 2011.

Citation: Koshimizu H, Fukui Y, Takao K, Ohira K, Tanda K, Nakanishi K, Toyama K, Oshima $M$, Taketo $M M$ and Miyakawa T (2011) Adenomatous polyposis coli heterozygous knockout mice display hypoactivity and agedependent working memory deficits. Front. Behav. Neurosci. 5:85. doi: 10.3389/fnbeh.2011.00085

Copyright (c) 2011 Koshimizu, Fukui, Takao, Ohira, Tanda Nakanishi, Toyama, Oshima, Taketo and Miyakawa. This is an open-access article distributed under the terms of the Creative Commons Attribution Non Commercial License, which permits non-commercial use, distribution, and reproduction in other forums, provided the original authors and source are credited. 